\title{
Erratum to: Blood Selenium Status in Normal Punjabi Population of Pakistan
}

\author{
Farrakh M. Alvi • Mohammad Anwar Chaudhri • \\ John Watling • Shahida Hasnain
}

Published online: 1 October 2011

(C) Springer Science+Business Media, LLC 2011

Erratum to: Biol Trace Elem Res (2011) 143:163-166

DOI 10.1007/s12011-010-8867-y

The original version of this article unfortunately contained mistakes. The last sentence of the abstract should read "Compared with other populations of the world these values are similar with the exception of the low-seleniumregion of China" instead of "Compared with other populations of the world, these levels are amongst the lowest".

The online version of the original article can be found at http://dx.doi. org/10.1007/s12011-010-8867-y.

F. M. Alvi $\cdot$ S. Hasnain

Department of Microbiology and Molecular Genetics,

University of the Punjab,

Lahore 54590, Pakistan

M. A. Chaudhri $(\square)$

Institut fuer Arbeits-, Sozial- und Umwelt Medizin,

University of Erlangen-Nuernberg,

Schiller Str. 25,

91052 Erlangen, Germany

e-mail: anwar.chaudhri@gmx.net

J. Watling

Department of Forensic Science, University of Western Australia,

Perth, Australia 